\title{
Interpretación agustiniana de algunos salmos difíciles
}

La hermenéutica, como arte de la interpretación ha tenido un amplio desarrollo en la lectura de los Salmos, quizá más que en ningún otro libro del A.T. Y es que aquí concurrían dos condiciones imprescindibles para que floreciera la hermenéutica: de un lado los Salmos ofrecen una visión de Dios, del mundo y del hombre, en definitiva, una espiritualidad que no podía llamarse cristiana en todos sus puntos; de otro lado, los Salmos forman parte de una tradición, que a toda costa se ha querido conservar. La interpretación se convertía así en el puente necesario que uniera las dos orillas distantes. Si a esto añadimos que el salterio se convirtió muy pronto en el libro privilegiado de la oración de la Iglesia, resulta comprensible, no sólo que la hermenéutica fuese necesaria, sino que tomara una dirección casi exclusiva: cómo y de qué manera «cristianizar» los Salmos.

S. Agustín dedicó a esta labor una obra muy voluminosa, las Enarrationes in Psalmos. En esta obra hace resaltar los valores cristológicos y parenéticos, dogmáticos y devocionales del salterio. Para ello se vale de un método de interpretación que consiste en suponer como sujeto del salterio, el Christus totus, es decir, Cristo personalmente o Cristo en cuanto cabeza de todo el cuerpo de la Iglesia. Pero esta labor de cristianización de los Salmos no siempre es fácil.

Hace algún tiempo $\mathrm{H}$. Weber ${ }^{1}$ publicó un artículo en el que exponía la interpretación que S. Agustín hace de los Fluchpsalmen, es decir, de los Salmos imprecatorios y de maldición, cuyo rezo aún hoy ofrece cierta dificultad. Las conclusiones a que llegaba eran las siguientes: los enemigos contra los que $443-450$

1. H. WEBER, «Fluchpsalmen in augustinischer Sicht»: Theologie und Glaube, 48 (1958) 
tantas maldiciones se echan en el salterio, son para S. Agustín, los demonios, las inclinaciones perversas, los vicios, incluso, a veces los hombres malvados, en cuanto que son prevaricadores.

Siguiendo la misma dirección de Weber, quisiéramos fijarnos en otros Salmos, cuya cristianización no es fácil, precisamente porque connotan una mentalidad no cristiana. Baste pensar en los salmos que respiran violencia o animan a una actitud intolerante frente a los malvados. Igualmente deben citarse los Salmos tradicionalmente tenidos por mesiánicos, que hablan de un personaje político y belicoso, rasgos que un cristiano no encuentra precisamente en Cristo. De otra parte, es opinión común que en los Salmos no se encuentra creencia alguna en la otra vida; algunos incluso abiertamente la niegan. Otros Salmos manifiestan una identificación entre la causa propia del fiel con la causa de Dios, que resultan repelentes, para quien piense que a Dios no se le puede manipular. No faltan tampoco Salmos que muestran un excesivo deseo de recompensa, sentimiento que escandalizaba a la misma Sta. Teresa de Lisieux ${ }^{2}$.

Hemos mencionado algunas de las deficiencias que un cristiano puede encontrar hoy en el rezo de los Salmos ${ }^{3}$. Decimos hoy intencionadamente, porque mucho depende del tipo de espiritualidad que esté de moda, digámoslo así, en cada momento de la historia de la Iglesia. Una espiritualidad pietista leerá con horror las imprecaciones del salterio; una espiritualidad más abierta y autocrítica o comprometida comprenderá hasta cierto punto las imprecaciones, pero le resultará intolerable la identificación de la propia causa con la causa de Dios. Esta diferente apreciación puede depender también del tipo de lectura que se haga. Así, por ejemplo, S. Agustín no apreciará la excesiva identificación de la propia justicia con la causa de Dios. Ello es debido a que pone el Salmo respectivo en boca de Cristo y naturalmente la causa de Cristo y de Dios coinciden. Esto sucede, por ejemplo, con el Sal 26(25). Este Salmo en nada se diferencia de la oración que Jesucristo pone en boca del fariseo en la conocida parábola de Lucas sobre el fariseo y el publicano (Lc 18, 9-14). Otro ejemplo podría ser el Sal 44(43). Es una lamentación nacional. Como es normal en este género literario, el pueblo se lamenta de la situación presente en forma dramática y patética. Esta situación tan lamentable es contrapuesta al glorioso pasado cuando Dios intervenía en favor de Israel. Pero a partir del v. 18 el salmo sigue un camino propio: «Todo esto nos sucede sin haberte olvi-

2. Historia de un alma. Burgos 1955, 508.

3. Sobre estas dificultades en el rezo de los Salmos véase E. BERNIMONT, «De l'inégale valeur des Psaumes»: Nouvelle Revue Theologique, 84 (1962) 843-852; J. FICHTNER, «Ist das Beten aller Psalmen der christlichen Gemeinde möglich und heilsam?: Gottes Weisheit. Gesammelte Studien z. A.T. Stuttgart 1965, 67-87. 
dado, sin haber violado tu alianza, sin que nos volviéramos atrás ni se desviaran de tu senda nuestros pasos»... Esta acusación gravísima y sin rubor alguno, S. Agustín no la aprecia, al leer el salmo cristológicamente. Sin embargo, esta cristologización tan rígida de la oración sálmica agudiza otras dificultades: ¿cómo atribuir a Cristo destronamiento de reyes, destrucción de naciones, amontonamiento de cadáveres en un baño de sangre?

Antes de exponer cómo lee S. Agustín estos Salmos un tanto especiales, conviene tener en cuenta dos puntos que atañen a la hermenéutica.

En primer lugar, para S. Agustín, como, por lo demás, para toda la $\mathrm{Pa}$ trística, la Escritura, tanto del A.T. como del N.T. contiene a Cristo y nada más que a Cristo ${ }^{4}$. Esto es particularmente más acentuado si se trata de los Salmos. Éstos son discursos proféticos de Cristo y de la Iglesia ${ }^{5}$. Que Cristo fue anunciado en tiempo precristiano es algo que para él no necesita probarse ${ }^{6}$. Sólo debe presumir haber entendido los Salmos, quien haya encontrado a Cristo en ellos ${ }^{7}$. Cristo es quien habla en los Salmos, en nombre propio o en nombre de la Iglesia, es decir, sus miembros. Estas ideas las repite constantemente y han sido expuestas repetidas veces ${ }^{8}$.

Otra premisa que conviene resaltar es el concepto que él tiene de la inspiración. Nos baste señalar aquí que en S. Agustín hay una tendencia clarísima a afirmar lo que hoy llamaríamos inspiración verbal. Las mismas expresiones materiales son obra de Dios ${ }^{9}$. Un indicio de ello es la creencia que tiene en la versión de los LXX. Entre las razones que da, apunta ésta: el mismo Espíritu que habló a los profetas cuando escribieron actuaba en los 70 varones cuando tradujeron ${ }^{10}$. Por lo mismo cuando hay alguna diferencia entre el texto hebreo y los LXX, ello no es debido a una traducción defectuosa, sino que, como estaban inspirados, hay que ver en ello una intención profética ${ }^{11}$. Y es que

4. S. Agustin, Contr. Faustum, 16,9: CSEL, 25,447: «Sed quia Moyses omne quod scripsit, de Christo est, id est ad Christum omnino pertinet, sive quod eum figuris rerum vel gestarum vel dictarum praenuntiet, sive quod eius gratiam gloriamque commendet...

5. S. Agustin, En. in Ps. 73,17: CC, 39,1015: "Cum magna voluptate audiuntur, quia audita etiam in orbe terrarum cognoscuntur. Haec quando dicebantur, non fuerunt; quia tunc promittebantur, non reddebantur; nunc vero qua voluptate afficimur, cum ea quae praedicta legimus in libro, compleri videmus in mundo!».

6. H. WiEland, Offenbarung bei Augustinus. Mainz 1978, 116.

7. En. in Ps. 96,2: CC, 39,1354-5: «Totum ad Christum revocemus, si volumus iter rectae intellegentiae tenere... Quidquid dubitationis habet homo in animo auditis scripturis Dei, a Christo non recedat; cum ei fuerit in illis verbis Christus revelatus, intellegat se intellexisse, antequam autem perveniat ad Christi intellectum, non se praesumat intellexisse».

8. Véase, por ejemplo, M. PonTET, L'Exégèse de S. Augustin prédicateur. Paris 1946.

9. H. Wieland, Ob. cit., 118-129; H.J. Vogels, St. Augustins Schrift De consensu Evangelistarum unter vornehmlicher Berücksichtigung ihrer harmonistischen Anschaungen. Bibl. Studien, XIII, 15. Freiburg 1908, 64ss.

10. S. Agustin, De civ. Dei, 18,43: CC 48,639: «Spiritus enim, qui in prophetis erat, quando illa dixerunt, idem ipse erat etiam in septuaginta viris quando illa interpretati sunt».

11. Ib. CC 48,640 . 
S. Agustín equipara los hagiógrafos a los profetas. A unos y otros les atribuye la revelación. Lo que escriben, lo oyen en su espíritu de una manera secreta y oculta, pero real ${ }^{12}$.

Estas dos premisas, cristologización rígida e inspiración verbal, debieran llevarle a callejones sin salida, cuando se encuentra con Salmos, cuyo tenor no se ajusta a la mentalidad cristiana. La única manera de salir del conflicto será recurrir a una exégesis alegórica y tipológica que en la mayor parte de los casos es una recreación del Salmo. Y entonces el Salmo, así domesticado, puede leerse cristianamente.

\section{Salmos violentos}

Un buen ejemplo de estos Salmos intratables es el 149. Es un himno; tiene por tanto, un tono festivo y laudatorio, pero esta alabanza a Dios va unida a una actitud guerrera y violenta que salta a primera vista. Ya Gunkel veía en él un canto para la danza de las espadas semejante a Ez 21, 14-21. Se trataría de una especie de baile ritual en que los actores blandiendo espadas en las manos, lanzaban hurras y alabanzas a Yahvé, celebrando la victoria por adelantado. Sea lo que fuere de este baile de espadas, lo cierto es que el v. 6 es clave para la interpretación del Salmo. Se invita a los participantes llamados «hasidim» a tener en sus bocas alabanzas al Señor y en sus manos espadas de doble filo. Hoy diríamos que estos tales deben tener en una mano la cruz y en la otra, la espada. Así armados se entregan a una acción que es así descrita: «hacer venganza a las naciones, represalias contra pueblos, sujetando a reyes con cadenas y a sus nobles con esposas de hierro. Ejecutar la sentencia dictada, es un honor para todos sus fieles» (vv. 7-9). Los protagonistas del Salmo son los «hasidim», «los leales», que son mencionados tres veces. Particularmente significativa es la expresión «qehal hasidim», que es la única vez que aparece en el texto hebreo. En 1Mac 2,42 se encuentra la equivalente expresión griega: «en aquellos días se unió a los Macabeos un grupo de los «hasidim» (sinagoge ton asidaion, trad de «qehal hasidim»), los fuertes de Israel, todos voluntarios de la Ley». Estos «hasidim» constituían las fuerzas de choque de los Macabeos y en ellos encontramos las dos características señaladas en el Salmo: oración en los labios y espadas en las manos (1Mac 3,18; 4, 9-13; 9, 31-47; 10,21; 2Mac 15,17.27). Estos «hasidim» son los hijos de Sión, los adictos a la causa de Sión, que no confían a Dios el exterminio de los enemigos, sino que ellos mismos se ofrecen como verdugos de Dios, sacerdotes de un rito sanguinario.

12. S. Agustín, En. in Ps. 109,7: CC 40,1606: «Audivit hoc David, audivit in spiritu, ubi nos, quando audivit, non audivimus... Audivit ergo prorsus, audivit in quodam secretario veritatis, in quodam mysteriorum sanctuario...». 
Tan justa es su acción militar, que en su actividad se cumple la sentencia dada por Dios. Oponen violencia a violencia y naturalmente la violencia con la que ellos responden, se identifica con la causa de Dios.

Desde el punto de vista cristiano, el Salmo es reprobable. Para Jesucristo las espadas están bien en la vaina (Mt 26,52) y la armadura del cristiano para S. Pablo es la fe, el amor, la paz y la justicia $(1$ Tes 5,8$)$, es decir, lo contrario de lo que predica el Salmo.

Veamos cómo lee S. Agustín este Salmo. Comienza señalando que el Salmo invita a alabar a Dios con un cántico nuevo. Hace una asimilación entre canto nuevo $=$ hombre nuevo $=$ Nuevo Testamento, y por otro lado, canto viejo $=$ hombre viejo $=$ Viejo Testamento . Como en el A.T. se hallan las promesas terrenales, el cántico nuevo debe cantar las cosas eternas y nuevas; y lo nuevo es el amor. La invitación, el Salmo está, pues, dirigido a todos los renovados en Cristo.

Como es canto de amor, es canto de paz y caridad. Quien se separa de la congregación de los Santos, no canta este cantar, aunque en sus voces resuene la alabanza a Dios; sus obras, empero manifiestan que se encuentra fuera, porque la discordia no es agradable a Dios. El Salmo, en efecto, prosigue diciendo que la alabanza debe resonar «en la iglesia de los santos». Esta iglesia es la iglesia de trigo sembrado en toda la tierra, no exclusivamente en África. Clara aquí aparece una alusión a los donatistas, asentados exclusivamente en África. Ésta, la iglesia donatista, no puede ser la iglesia de los santos, a tenor de la parábola del sembrador, en la que Cristo expresamente señala que el campo sembrado es el mundo entero.

El Salmo, pues, es totalmente cristiano y sólo los renovados en Cristo, unidos por la caridad pueden cantarlo. Alguna dificultad a esta apropiación podía ofrecer el v. 2: «Alégrese Israel en su Hacedor». Pero valiéndose de sus técnicas de gramático resuelve fácilmente la perplejidad: «Israel» significa el que ve a Dios. Los que ven a Dios deben alegrarse en su Hacedor. ¿Acaso los cristianos ven a Dios? Naturalmente que sí, aunque sólo por la fe; si creemos y amamos, vemos ${ }^{13}$. Y no dejará pasar la ocasión de extraer una lección para su tiempo: hay que alegrarse en el supremo Hacedor, no en Arrio, ni en Donato o Ceciliano, ni tampoco en Agustín.

Una nueva oportunidad para insistir en la unidad de la Iglesia se la ofrece el versículo siguiente: «Laudent nomen eius in choro». La Iglesia es un coro de cantores, donde todos tienen que hacerlo al unísono. Los herejes perturban la armonía. Más atrevida es aún la aplicación que hace a continuación: «con el tímpano y el salterio deben los cristianos alabar a Dios». ¿Qué otra cosa quie-

13. En. in Ps. 149,4: CC 40,2181: «Si credimus, videmus; si amamus, videmus». 
re decir esto, sino que la alabanza debe ir acompañada con las obras, de la misma manera que la voz es acompañada con los instrumentos musicales? Pero no se detiene aquí la explicación. Hay otro misterio escondido en la mención de los instrumentos musicales: en el tambor se extiende el cuero; en el salterio, las cuerdas; en ambos instrumentos se crucifica la carne; una invitación, pues, al dominio de la concupiscencia. Cuanto más se mortifique la carne, mejor sonará la alabanza divina en los labios.

Ninguna dificultad encuentra al entender cristianamente el v. 4: «porque el Señor benefició a su pueblo». Del v. 5, por su parte, extrae una lección moral: «los Santos se regocijarán en gloria». Contrapone la gloria de los santos a la gloria mundana, particularmente de los espectáculos de los gladiadores en el circo. Los santos, en cambio, se alegran en sus moradas. «Sus moradas» quiere decir, según él, sus conciencias y cita en su apoyo 2 Cor 1,12: «Nuestra gloria consiste en el testimonio de nuestra propia conciencia». Pero no se le escapa a Agustín que este gloriarse de la propia conciencia es ambiguo, porque pudieran complacerse en sí mismos, envanecidos por su conciencia irreprochable. Es por esto por lo que el Salmo prosigue: «las alabanzas de Dios en sus bocas». De tal modo se regocijan en su conciencia que no atribuyen a sí mismos el ser buenos, sino que alaban a Aquel de quien recibieron lo que son.

Veamos ahora la explicación de la frase siguiente: «y espadas de doble filo en sus manos». Estas espadas de doble filo encierran un gran misterio: las espadas de doble filo son la palabra de Dios ${ }^{14}$. No le causa dificultad alguna, el que se diga espadas en plural, pues muchas son las bocas y las lenguas de los santos que la predican. El punto de apoyo para esta interpretación no podía ser otro que el texto de Heb 4,12, donde la palabra de Dios es comparada a una espada de doble filo. También para este detalle, el doble filo, encuentra su explicación: la palabra de Dios promete cosas temporales y eternas, el A. y N. Testamento. Agustín percibe el carácter terrible de la espada de doble filo. Pero precisamente la palabra de Dios tiene este carácter eficaz: ella corta, divide, separa al padre del hijo, a la hija de la madre. Pero aún queda otra dificultad: si la espada es la palabra de Dios, ¿por qué se dice que la llevan en las manos y no en la lengua? En las manos quiere decir en poder. Estos predicadores llevan la palabra de Dios en poder, porque sin temor alguno predican a los poderes humanos. Para apoyar esta opinión no le cuesta trabajo alguno aducir un texto en que mano equivale a poder en un contexto de predicación profética: $\mathrm{Ag}$ 1,1: «factus es sermo Domino in manu Aggaei prophetae».

Armados así los santos libran gloriosas batallas. S. Agustín se da cuenta del carácter marcial e intrépido del Salmo. ¿Cuál es la actividad de los santos?

14. Ib. 12: CC, 40,2185. La misma equiparación en En. in Ps. 44,11: CC, 38,501: «Gladium tuum, quid, nisi verbum tuum». 
Hacer venganza en las naciones, dice el Salmo. Todos los días tiene lugar esta venganza. Agustín mismo libra esta batalla predicando. ¿Cómo dan muerte a las naciones? Haciéndolas cristianas. Esta interpretación no debe parecer extraña, razona el Santo, puesto que en la visión que tuvo Pedro, se le dijo: «Mata y come» (Hech 10,13). En ningún caso debe pensarse que los santos maten, derramen sangre, causen heridas materiales, pues la segunda parte del versículo lo aclara suficientemente: «los santos hacen reprensiones en los pueblos» ${ }^{15}$.

Pero a S. Agustín, orgulloso de haber aclarado un texto oscuro, le sale al paso una nueva dificultad: ¿cómo entender que estos predicadores aprisionan a sus reyes con grillos y a sus nobles con esposas de hierro? (v. 8). También aquí se sirve de la S. Escritura para dar una interpretación. «Dios escogió lo flaco del mundo, para confundir a lo fuerte... no hay entre vosotros muchos sabios ni muchos potentes ni muchos nobles; pero lo débil del mundo lo escogió Dios para confundir a los fuertes» (1Cor 1, 26-28). Los santos, armados con la espada de doble filo, fueron enviados a predicar. Muchos reyes y nobles se convirtieron e incluso abandonaron el poder y la riqueza y se encaminaron a la perfección. Otros retienen el poder, pero son cristianos. Éstos son los reyes y nobles, atados con cepos de hierro, pero, ¿por qué tienen grillos de hierro y no de oro? Son de hierro, mientras temen; amen y serán de oro. A los reyes y nobles que tienen poder y haberes se les amenaza con el suplicio eterno mediante la palabra de Dios y son encadenados con grillos. Aun no aman la justicia, pero temen el castigo y al temer el castigo, ya tomaron los grillos y son adoctrinados con las cadenas de hierro ${ }^{16}$.

Finalmente, el Salmo termina afirmando que los santos haciendo esto ejecutan el juicio decretado. ¿Por qué juicio decretado? Porque anteriormente fueron escritas estas cosas y ahora se cumplen. Los Salmos son una profecía que antes sólo se leía; ahora se realizan totalmente ${ }^{17}$.

Nos hemos extendido largamente sobre la interpretación agustiniana de este Salmo, porque nos parece paradigmático para entender cómo él lee los Salmos, particularmente los violentos.

En primer lugar, cabe señalar, la interpretación rígidamente cristiana. En nuestro caso, el Salmo no tiene otro objeto que anunciar anticipadamente la práctica de la Iglesia. Antes sólo era posible leerlo, ahora lo que se anunció y no se entendía, se ve realizado. Éste es el sentido del Salmo, otro no tiene. Si se quiere saber cómo Agustín llega a interpretar este Salmo de una manera tan

15. En. in Ps. $149,13:$ CC, $40,2187$.

16. Ib. 15: CC 40,2189.

17. Ib. 16: CC 40,2190: «Ista antea conscripta sunt, et modo complentur. Ecce modo fiunt aliquando legebantur et non fiebant». 
arbitraria a primera vista, es conveniente tener en cuenta el doble criterio de interpretación, que encuentra en este Salmo su aplicación. Uno es que los lugares claros de la Escritura, deben servir para aclarar los oscuros ${ }^{18}$. Así en el Salmo que hemos expuesto, si se equipara la espada de doble filo a la palabra de Dios, es porque las encuentra ya así asimiladas en la Carta a los hebreos. Que la predicación pueda insinuarse en un lenguaje sangriento, aparece en los Hechos de los Apóstoles. Que se diga que la palabra de Dios se lleva en la mano, no es nada raro; la misma manera de hablar aparece en los profetas. No cabe duda que el principio de interpretar la Escritura por ella misma es válido. Su aplicación en cambio, en S. Agustín, no lo es tanto. Encadena los textos unos con otros por asociación de ideas o por mera aproximación verbal, sin espíritu crítico. Así, por ejemplo, para saber qué significa espada de doble filo en el Salmo, la Carta a los Hebreos no ilumina mucho, pues en ella es la palabra de Dios la que es comparada a una espada; esto no prueba que en el Salmo signifique la palabra de Dios. Por otra parte, no hay que olvidarse que la exégesis de S. Agustín, sobre todo cuando predica, no es una explicación del texto, una lectura en busca del sentido que intenta el autor. El hablar bíblico es para él un lenguaje en signos, es una especie de aproximación a la verdad. La verdadera intelección del texto se da por la iluminación interior con ocasión de la lectura del texto mismo. Lo importante no es interrogarse por la intención del autor, sino por lo que dice el texto en relación con la verdad misma ${ }^{19}$. Que esto lleva consigo dejar un amplio campo a la arbitrariedad, es indudable. De hecho S. Agustín no se limita a leer los Salmos, los recrea, hace un Salmo nuevo. El Salmo 149 es buen ejemplo de ello. Es la iglesia de los santos, es decir, la iglesia cristiana, la que es invitada a alabar a Dios en coro, es decir, unánimente. Esta alabanza, a Dios dirigida en la Iglesia cristiana es un cántico oral, pero debe ir acompañado de las buenas obras. Con la misma vida hay que alabar a Dios. Buenas razones tiene para ello: Dios ha redimido a su pueblo. De ello se alegran los santos de la iglesia y se glorían en sus conciencias, pero no por lo que hacen, sino por lo que Dios ha hecho. Disponen además de la palabra de Dios, la espada de doble filo, con la que vencen a los pueblos y naciones, haćéndolas cristianas. De esta manera, encadenan a reyes y nobles, sometiéndoles al temor cristiano e incluso llevándoles a la perfección. No cabe duda de que lo que hace aquí S. Agustín es un Salmo nuevo. Poco o nada queda del antiguo Salmo. La actividad de la Iglesia, que aquí se canta, poco o nada tiene que ver con la actividad que se atribuían a sí mismos los «hasidim» del tiempo de los Macabeos.

Otro principio interpretativo que establece Agustín es la «regula fidei» o

18. H. WiELAND, Ob. cit., 200-201.

19. Ib. $135-136$. 
práctica de la Iglesia ${ }^{20}$. Este principio es aplicado en la lectura de nuestro Salmo. Es una profecía de Cristo y de la Iglesia. Como ésta, hoy no hace lo que a primera vista parece decir el Salmo: la iglesia no hace venganza en las naciones, no encadena reyes ni emplea la espada, es preciso buscar una explicación más suave y leve, que, aun cuando conserve el carácter intrépido del Salmo, excluya, sin embargo, su aspecto sanguinario. Permanece así una aura intransigente, pero es la intransigencia y el celo del predicador cristiano: sus armas no son de hierro, sino la palabra de Dios. No hay unión entre la cruz y la espada; sí, en cambio, intransigencia entre lo que Dios exige y los compromisos humanos.

A esto hoy llamaríamos una labor de domesticación. El Salmo es privado de las aristas, que le hacían inaceptable para una mentalidad cristiana.

\section{a) Salmo 47(46)}

Es un ejemplo típico de los himnos a Yahvé Rey, como los salmos 94-100. Pero éste es más enérgico, marcial. Es una especie de himno nacional del estado teocrático. La simbología empleada manifiesta el tono exaltado. Hay una simbología espacial: Yahvé es el Altísimo; las naciones yacen bajo los pies de Yahvé y de Israel. A esta simbología vertical se mezcla la horizontal: Yahvé domina sobre lo ancho de la tierra. Naturalmente domina el simbolismo real, propio del lenguaje cortesano: tres veces se afirma que Yahvé es rey, la mención del trono, el sentarse o entronización de Yahvé, el grito de la «terua», o grito ensordecedor de origen bélico que pasó a la liturgia. En medio de este ambiente exaltado, lleno de gritos y de alegría aparece impresionante la figura de Yahvé Rey, al que se le dan tres títulos, como si se tratase del protocolo real: Él es el Altísimo, el Terrible, el Rey grande sobre toda la tierra. Éste es el protagonista de la fiesta en toda su brillantez. A esta Teofanía sigue la descripción de un doble acto de Yahvé: triunfo sobre las naciones y elección de Israel.

Nos interesa la primera acción. Al gran Rey Yahvé aparece asociado el pueblo (o mejor el rey de Israel), no mencionado expresamente, pero que se le supone compartiendo el trono real de Yahvé, ya que a sus pies yacen los pueblos sometidos (v.4). Esta frase es singular dentro de los Salmos del Reino de Yahvé. Es claro que hay en él una nota de triunfalismo político y chovinista, una identificación entre el Reino de Israel y el Reino de Dios que resulta repelente. Un cristiano no sabe qué hacer con él.

20. S. Agustín, De doc. Christ. III, 2,2: CC 32,78: «Consulat regulam fidei, quam de scripturarum planioribus locis et ecclesiae auctoritate percepit...». 
S. Agustín se da cuenta de la dificultad, al menos en parte y se pregunta: «¿Qué pueblos sometió y a quiénes? ¿Quiénes son los que hablan? ¿Acaso los judíos? Se entiende perfectamente si son los Apóstoles, si son los santos los que hablan. A éstos sometió Dios los pueblos y naciones» ${ }^{21}$. Prueba de ello sería que hoy son venerados por las naciones los Apóstoles, que murieron a manos de sus conciudadanos. Pero esta interpretación no le satisface. Confiesa ignorar si es correcta o no. La razón, para él es sencilla: sería chocante, dice, que los apóstoles hablasen tan soberbiamente de suerte que se alegrasen de tener todas las naciones, es decir, a los cristianos bajo sus pies, cuando son ellos los que se alegran de estar con nosotros a los pies de Cristo. $Y$ en apoyo de esto, aduce el testimonio de Pablo $(1$ Cor 1,13$)$ que niega que él haya sido crucificado por los cristianos. Bajo sus pies, Pablo no quiere a nadie; a todos, en cambio, los quiere a los pies de Cristo. Es obligado, pues, buscar otra explicación y es ésta: «Tanto los que pertenecen a la heredad de Dios como los que no pertenecen a ella, se hallan en todas las naciones y contempláis que de tal modo es exaltada la Iglesia de Cristo, que todos los no creyentes yacen a los pies de los cristianos. ¿Cuántos que aún no son cristianos, corren ahora a la Iglesia, piden la ayuda de la Iglesia! Quieren ser socorridos temporalmente, aunque no quieren reinar con nosotros eternamente. Al buscar la ayuda de la Iglesia, aun los que no pertenecen a ella, ¿no manifiestan que están sometidos los pueblos y naciones bajo los pies de los cristianos? ${ }^{22}$.

Es realmente curioso que no se atreva a poner en boca de los Apóstoles el versículo citado, porque lo considera lleno de soberbia, y, en cambio, no tenga escrúpulo alguno en ponerlo en boca de los cristianos. Es una pena, además que no siguiera la pista que él mismo insinúa: poner la frase en boca de los judíos. Pero naturalmente, esto es imposible, tratándose de un Salmo tan cristológico a su entender. En todo caso el sometimiento de las naciones ya no es político. Agustín ve la sujeción de los paganos en el hecho de que éstos acuden a la Iglesia en busca de ayudas temporales, alusión, sin duda alguna, a la obra benefactora de la Iglesia con los pobres, que los mismos pobres consideraban normal ${ }^{23}$. También aquí asistimos a una domesticación del salmo. La regla de interpretación es la práctica cristiana.

b) Salmo 2 y 110(109)

Son dos salmos célebres, interpretados cristológicamente en la tradición y tenidos por mesiánicos aun hoy por algunos, aunque uno no sabe qué pueda

21. S. Agustín, En. in Ps. 46,5: CC 38,531: «Qui sunt qui loquuntur? Forte Iudaei? Plane si Apostoli, plane si sancti. His enim Deus subiecit plebes et gentes».

22. Ib. 5: CC 38,532.

23. B. RAMSEY, «Almsgiving in the latin Church. The late fourth and early fith centuries»: Theological Studies 43 (1982) 226-259, espec. 231-2. 
significar este término, aplicado a este par de Salmos. Son muy semejantes entre sí. Pertenecen al grupo de Salmos reales, como los siguientes: 20,21,45,72, 89 y 132 . Estos dos, el 2 y 110 , tienen el mismo «Sitz im Leben»: la entronización del rey de Israel. Esta situación provoca que la simbología empleada sea eminentemente convencional, propia del estilo cortesano, en el que la exaltación patriótica y el entusiasmo nacionalista y militarista es normal. El ambiente es bélico y guerrero; el interregno lo aprovechaban los vasallos para rebelarse, por eso hay rumores de guerras y rebeliones y campañas militares para dejar las cosas en su sitio. El nuevo rey, legitimado por la proclamación de la filiación divina, goza de la protección de Dios para llevar a cabo empresas militares, en las que abate reyes adversarios; lleno de furor, emite sentencias capitales, eleva montones de cadáveres y abre cráneos enemigos. La retórica nacionalista junto con una exaltación estilística son características notables de estos Salmos, que, junto con la conexión e identidad que se afirma, hay entre las miras de Dios y el Rey de Israel, hacen inevitable una transformación del Salmo para que sea legible y asimilable a una mentalidad cristiana.

Del Salmo 2 S. Agustín sólo dejó unas notas escuetas y no un sermón predicado al pueblo. La lectura cristológica es para él obligada ${ }^{24}$. Ve en el Salmo una historia real de Cristo y de su Iglesia. Las naciones que se rebelan contra Dios y su Ungido son los perseguidores del Señor, de quienes se habla en $\mathrm{He}-$ chos $(4,26)$, que trataron de sacudir el yugo de la Religión cristiana ${ }^{25}$. Sin embargo, es vano este intento. Porque el Señor Jesús es constituido Rey sobre su Iglesia. Así entiende él a Sión, que significa «contemplación». ¿Quién contempla mejor que la Iglesia continuamente dedicada a explorar la claridad divina?

Y tras señalar que la afirmación del Salmo sobre la filiación divina, debe entenderse de la generación eterna del Verbo, pasa a examinar los versículos siguientes que son más comprometedores. «Pídeme y te daré en herencia las naciones». La petición se dirige a que las naciones se congreguen bajo el nombre cristiano «a fin de que las poseas para su salud y te produzcan frutos espirituales» ${ }^{26}$. El gobierno con cetro de hierro y la destrucción de las naciones de que se habla en los vv. 9-10 del Salmo, es leído en clave espiritual e incluso assunt».

24. En. in Ps. 2,5: CC 38,5: «Ex persona ipsius Domini nostri Iesu Christi ista manifesta

25. En. in Ps. 2,7: CC 38,4: «Demus operam ut non nos alliget, neque imponatur nobis Religio christiana».

26. En. in Ps. 2,7: CC 38,5: «Ut scilicet gentes nomini christiano copulentur atque ita a morte redimantur, et possideantur a Deo. Dabo tibi gentes hereditatem tuam, quas possideas ad earum salutem, et quae tibi fructificent spiritalia». 
cética: «quebrantarás en ellos los deseos terrenos y las ocupaciones inmundas del hombre viejo y todo lo que contrajeron y brotó del limo pecador ${ }^{27}$.

Del Salmo 110(109) ha dejado Agustín un sermón, por cierto muy largo y con muchas digresiones. Para él el Salmo es una profecía de Cristo ${ }^{28}$. No se puede dudar de ello, porque Cristo se lo aplicó a sí mismo en polémica con los judíos (Mt 22, 42-45), señala Agustín. El Salmo proclama la exaltación de Cristo: «sede a dextris meis» y al mismo tiempo el dominio sobre todas las naciones. La primera parte, la exaltación de Cristo es oculta y secreta, pero la otra, la colocación de los enemigos a sus pies es abierta y manifiesta ${ }^{29}$. Este sometimiento de las naciones se hace continuamente, sin interrupción alguna ${ }^{30}$. Llegados aquí, ya nos imaginamos cómo interpretará el sometimiento de las naciones a Cristo. Por supuesto, no se trata del reino aquel que Cristo comparte con el Padre, por ser Señor de todas las cosas. Se trata, sin duda alguna, del «reino transitorio y administrativo por el que nos llamó a la eternidad mediante su carne y que comienza en los cristianos» ${ }^{31}$. El dominio, pues, de Cristo es actual, se ejerce ya en los cristianos y se extiende a todas las naciones, llevándose a cabo por medio de la predicación y conversión. Sería incomprensible este versículo, si no viéramos que ya acontece ${ }^{32}$. En definitiva Cristo somete los pueblos a su yugo, no con la espada, sino con la cruz ${ }^{33}$. Y uno debe preguntarse si San Agustín no ha ido demasiado lejos. Ha enmendado la plana al Salmo, mas que interpretarlo, si se tiene en cuenta el texto de los vv. 5 y 6 . El dominio se ejerce, según él, convirtiendo en humildes a los soberbios. Así entiende él el terrible versículo 6: «conquassabit capita multa super terram» ${ }^{34}$.

Hemos visto en todos los ejemplos la misma línea de interpretación. El sometimiento político de que hablaban los Salmos es transformado en conver-

27. En. in Ps. 2,8: CC 38,5: «Conteres in eis terrenas cupiditates, et veteris hominis lutulenta negotia, et quidquid de peccatore limo contractum atque inolitum est».

28. En. in Ps. 109,3: CC 40,1603: «Ex his promissionibus est Psalmus iste, Dominum et Salvatorem nostrum Iesum Christum certe aperteque prophetans; ut omnino dubitare non possimus Christum annuntiari Psalmo hoc»).

29. En. in Ps. 109,9: CC 40,1608-9: «Non vides Christum sedentem ad dexteram Patris; vel hoc potes videre, quomodo ponantur inimici eius scabellum pedum eius».

30. En. in Ps. 109,9: CC 40,1609: «Hoc fit, hoc agitur; etsi paulatim peragitur, indesinenter agitur».

31. En. in PS. 109,10: CC 40,1610: «Sed tamen illud dispensatorium et transitorium, quo nos per medietatem carnis suae vocavit in aeternitatem, regnum eius incipit a christianis».

32. En. in Ps. 109,11: CC 40,1610: «Hunc versum non recte intellegimus, si non fieri iam videmus».

33. En. in Ps. 109,13: CC 40,1613: «Quia enim et hic dicta est virtus eius, qua subiecit gentes iugo suo, qua stravit populos, non ferro, sed ligno, etsi in carne, etsi in humilitate... capitur tamen magna virtus eius».

34. En. in Ps. 109,19: CC 40,1620: «De superbis humiles facit». 
sión voluntaria, fruto de la predicación cristiana. Estas ideas las repite continuamente y las expone cuando comenta los Salmos 45(44) y 72(71), dos Salmos reales también ${ }^{35}$.

Otra línea de interpretación distinta creemos distinguir cuando interpreta el Salmo 21(20). En este caso escatologiza el Salmo. El Salmo 21 es un Salmo real como los anteriormente citados. Prescindiendo ahora de su «Sitz im Leben» que es discutido, el Salmo no puede espiritualizarse apresuradamente, dado el carácter litúrgico y la ideología monárquica subyacente. En el v. 9 la imagen es violenta. El rey de Israel aparece como un soldado sanguinario que triunfa sobre sus enemigos en medio de un baño de sangre, que alcanza incluso a la descendencia de sus enemigos.

De este Salmo S. Agustín sólo dejó unas notas y no un sermón. Con demasiado apresuramiento señala que el Salmo se refiere a Cristo («Christo canitur». In Ps 20,1). ¿Cómo salva la dureza de las expresiones de los vv. 9-11? Escatologiza el Salmo. Así parafrasea el v. 9: «tu poder, ;oh rey!, encuentre, cuando vengas a juzgar, a todos tus enemigos, que no conocieron tu poder en la humildad». Pero esto sucederá, cuando el Señor se manifieste al final de los tiempos. Consiguientemente el fuego devorador del que habla el Salmo se interpreta del fuego del infierno y el exterminio de la estirpe de los enemigos del rey lo refiere o a sus obras o a los que ellos sedujeron ${ }^{36}$.

Estas dos interpretaciones, la espiritual (sometimiento mediante la conversión) y la escatológica (destrucción de los enemigos al final de los tiempos) las yuxtapone cuando comenta el Salmo 68(67). Este Salmo es una oda difícil textual y exegéticamente, de alto valor épico, aunque carente a veces de simetría. Es un himno, pero también profesión de fe y memorial litúrgico, lleno de pasión y de colores encendidos con un lenguaje militar y de venganza. En los vv. 22-24 la imagen es bélica: «Dios aplasta la cabeza de sus enemigos, los cráneos cabelludos de los que caminan en el delito. Dice el Señor: 'los traeré desde Basán, los traeré desde el fondo del mar; bañarás tus pies en la sangre de tus enemigos y tus perros la lamerán con sus lenguas'». Aunque textualmente hay ciertas dificultades, el sentido más obvio es éste: Dios es presentado como un cruel soberano oriental que aplasta la cabeza, esto es, lo más selecto de las fuerzas enemigas. A continuación hace un peinado por el territorio en busca de enemigos que son puestos a los pies de Israel; éste podrá bañar sus pies en la sangre de los mismos y hasta los perros tendrán su porción.

35. ' En. in Ps. 44,16: CC 38,505: «Populi sub te cadent, in corde inimicorum regis». Inimici erant; acceperunt sagittas tuas, ceciderunt ante te. Ex inimicis amici facti sunt; inimici mortui sunt, amici vivunt». En. in Ps. 71,11: CC 39,980: «Hinc ergo doctrina eius incipiens et magisterii caelestis auctoritas, dilatatur usque ad terminos orbis terrae, cum praedicatur Evangelium regni in universo orbe, in testimonium omnibus gentibus».

36. En. in Ps. 20,11: CC 38,116. 
Agustín aplica estos versículos a Cristo que, aunque mofado y triste, no obstante, quebranta la cabeza de los enemigos. Esto lo hace de dos maneras: dando bienes por males sometiendo a sí a los creyentes, o dando justicia por injusticia castigando a los soberbios. Quebranta y pulveriza la cabeza de los enemigos destronándoles de su soberbia, bien corregidos mediante la humildad, o bien arrojándoles al infierno ${ }^{37}$. La doble lectura, de que hablábamos antes, es aquí patente. En todo caso, hay una acomodación del Salmo a las creencias cristianas, con la consiguiente suavización de las expresiones duras del Salmo.

En cuanto a los vv. 23-24, S. Agustín no percibe la imagen truculenta y terrible; al contrario, los interpreta «in bonam partem».

Los códices que él maneja tienen dos lecturas diferentes: «Ex Basan convertar» (Me volveré de Basán) o «ex Basan convertam (los haré volver de Basán)». Basán significa confusión y también sequedad: ambas son imágenes del pecado en el que están sumergidos los hombres. Por lo mismo el sentido puede ser doble: o bien que el Señor hace volver a los que yacían en el pecado, o bien que Él se ha de volver de allí para liberarlos. Seguidamente «ut tingatur pes tuus in sanguine» lo pone en boca del salmista que se lo dice a Cristo y el sentido es éste: «Estos liberados por ti de la región de la confusión y de la sequedad, o aquéllos a quienes te vuelves para librarlos se convertirán en tu pie dentro de tus miembros para anunciar tu Evangelio y soportarán un prolongado martirio por tu nombre hasta llegar a derramar la sangre» ${ }^{38}$. La siguiente frase «lingua canum tuorum ex inimicis ab ipso» la entiende también «in bonam partem». Los perros son los que luchan por el Evangelio y que antes eran enemigos y se han hecho fieles perros del Señor gracias a Él ${ }^{39}$. La interpretación no puede ser más alambicada, aunque en este caso las versiones que manejaba S. Agustín no le facilitan la labor.

\section{Salmos moralmente deficientes}

Juntamos aquí una serie de observaciones sobre los Salmos, o mejor, sobre ciertos versículos de los Salmos, que a S. Agustín le causan cierta dificultad, y se cree en la obligación de interpretarlos correctamente. Se trata de versículos que manifiestan deseos de venganza, de maldiciones, imprecaciones, manifestaciones de odio, ordalías, etc.

Un buen ejemplo nos lo ofrece el Salmo 7. El texto no es claro y la estructura es difícil. El género literario oscila entre una lamentación individual, un

37. En. in Ps. 67,30: CC 39,891: «Utroque enim modo conquassantur et confringuntur capita inimicorum cum a superbia deiciuntur sive humilitate correcti sive in ima tartari abrepti».

38. En. in Ps. 67,31: CC 39,892.

39. En. in Ps. 67,32: CC 39,892. 
juramento de inocencia o una liturgia del juicio de Dios. El elemento predominante es el juramento de inocencia que encontramos en otros lugares del salterio $(17,3-4 ; 26,4-6 ; 73,13 ; 89,35-36 ; 137,5-6)$. Este juramento era un elemento importante en el ámbito del derecho de asilo que tenía el templo.

Para San Agustín este Salmo lo recita no Cristo, sino el alma perfecta. En el v. 4 se encuentra el terrible juramento de inocencia u ordalía. S. Agustín se da cuenta de la figura literaria. Observa que se trata de un juramento con maldición, que es el más grave de todos los juramentos y ocurre cuando se dice: si hice esto, padezca esto. Pero no está dispuesto a admitir nada malo en los autores bíblicos; por ello soluciona así la dificultad: «Una cosa es la acción de jurar en la boca del que jura y otra en la significación de quien profetiza. Aquí dice qué cosa ha de suceder como cierta a los hombres que devuelven males a aquellos que retribuyen males; no que desee como con juramento algo para sí o para otro ${ }^{40}$. La interpretación que hace, no podía ser más forzada. Resulta sorprendente afirmar que la imprecación va dirigida a los que retribuyen males. De estos ciertamente el salmista no es; niega, en efecto, haber hecho esto y precisamente porque no lo ha hecho, es por lo que lanza esta imprecación contra sí mismo. Es una interpretación forzada, debido a que Agustín se ha dado cuenta de la figura literaria. La interpretación viene impuesta por un prejuicio dogmático; no puede admitirse nada malo en los autores de la S. Escritura.

Pero es conveniente notar que en el párrafo anterior encontramos una característica usual de la interpretación agustiniana de los Salmos: cuando en algún Salmo encuentra una maldición, un mal deseo, una imprecación, algo que en definitiva desde el punto de vista cristiano no es aceptable, advertirá siempre que se trata de una profecía, no de un deseo. Como profecía expone y declara por anticipado lo que sucederá; pero esto no lleva consigo que lo que se anuncia, se desee ${ }^{41}$.

Este recurso al carácter profético de los Salmos lleva consigo una escatologización de los males o castigos anunciados. La profecía anuncia por anticipado lo que al final del tiempo será una realidad. Esto es lo que dice expresamente comentando el v. 8 del Sal 101(100): «De madrugada mataba a todos los pecadores de la tierra». Por supuesto lo pone en boca de Cristo, pero aun así no deja de ser oscuro, advierte con razón. Pero cree que se puede explicar fácilmente si se atiende al comienzo del mismo Salmo: «Misericordia y juicio te cantaré, Señor». Ahora, dice, es el tiempo de la misericordia, es la noche en

40. En. in Ps. 7,3: CC 38,38: «Sed aliud est iuratio in ore iurantis, aliud in significatione prophetantis. Hic enim dicit quid vere contingat hominibus qui reddunt retribuentibus mala; non quod sibi, aut alicui, quasi iureiurando imprecetur».

41. En. in Ps. 78,14: CC 39,1107; En. in Ps. 78,16: CC 39,1109-1110: «Non mala optat; sed iusta praenuntiat, et ventura prophetat». En. in Ps. 82,9: CC 39,1143; Ib. CC 39,1144; En. in Ps. 108,7: CC 40,1588-89. 
que perdona. «Tolera para que los pecadores se conviertan a Él; pero quienes no se corrigen en este tiempo de misericordia, serán matados» ${ }^{42}$.

A veces encuentra estas profecías sálmicas ya realizadas y cumplidas, con lo que cree limpiar al salmista de un mal deseo. Así comentando el Sal 40(41) encuentra este versículo (v. 11): «Tu autem, Domine miserere mei, et resuscita me et reddam illis». En el contexto del Salmo, la idea no es muy aceptable: el fiel enfermo pide a Dios poder levantarse para devolver a sus enemigos lo que han hecho con él. S. Agustín, como se trata de un salmo de lamentación, lo pone en boca de Cristo en su naturaleza de siervo pobre y maltratado. La interpretación cristológica se debe también a que aparece en los Evangelios en boca de Cristo aplicado a Judas (Jn 13,18; cfr. Mc 14,18). Como por otra parte la versión latina que tienen, lee «resuscita me», la aplicación a Cristo no podía ser más evidente. De ahí que mitigue en extremo el deseo de venganza. En realidad ya no percibe en el Salmo deseo alguno, sino que ve en él una profecía cumplida: «Ved que cuanto se dijo, ya se ha cumplido. Los judíos mataron a Cristo para no perder el lugar; matándole perdieron el lugar; arrojados del reino, se dispersaron. Resucitado, les devolvió tribulaciones; se las devolvió para corregirlos no para condenarlos ${ }^{43}$.

Sin embargo, este recurso a la profecía, no le debía convencer mucho, a pesar de que lo repita tantas veces. El tema es más profundo. Con él se enfrenta al comentar el Salmo 79(78). Aquí encuentra el v. 10 que le parece difícil: «Et innotescat in nationibus coram oculis nostris ultio sanguinis servorum tuorum qui effusus est». También aquí repite su consabido recurso: «Estas palabras son proféticas, no deseo». Explicación, que por cierto, tiene que repetir muchas veces en este Salmo porque todo él está lleno de imprecaciones. Pero esta explicación no resuelve el asunto dado que el deseo de venganza se encuentra en textos del N.T., cuyo carácter profético no es reconocido. Cita en efecto Ap 6, 9-10 donde se habla de los mártires que están debajo del altar que clamaban y decían: ¿Hasta cuándo, Señor, tardarás en vengar nuestra sangre? Ha visto bien San Agustín que los dos textos son muy parecidos. El recurso al carácter profético ya no es suficiente. Desde el punto de vista cristiano hay que buscar otra explicación. Ahora bien, parte del supuesto de que no puede aceptarse que los santos deseen la venganza para saciar su odio. Esto desdiría de su perfección. Conviene notar este principio, que es más un prejuicio que otra cosa, porque el mismo S. Agustín se da cuenta de que contra este principio hay un Salmo que aparece bastante claro: «Letabitur iustus cum vi-

42. En. in Ps. 100,13: CC 39,1417: «Tolerat ut convertantur ad illum peccatores. Sed qui non se correxerint in isto tempore misericordiae, interficientur». Igualmente en En. in Ps. 53,9: CC, 39,653; En. in Ps. 54,11: CC 39,664-5; En. in Ps. 108,7: CC 40,1588-9.

43. En. in Ps. 40,12: CC 38,457. 
derit vindictam; manus suas lavabit in sanguine peccatoris» (Sal 58(57),11). Este texto crea dificultad, no sólo porque se afirma el deseo, sino incluso la alegría por la venganza esperada. Anota, por otra parte, un texto de Pablo, referente al mismo tema: «Carísimos, no os venguéis, sino dad lugar a la ira de Dios, pues está escrito: Para mí la venganza, yo daré el merecido, dice el Señor» (Rom 12,19). Anota San Agustín con razón, que Pablo aquí no impone que no quieran ser vengados, sino que no se venguen ellos mismos y den lugar así a la ira de Dios. Pero frente a esto, Jesucristo mismo en el Evangelio en la parábola de la viuda que acude a un juez injusto ( $\mathrm{Lc} 18,3-5)$ la propone como modelo y ejemplo de cómo Dios acudirá al clamor de los elegidos que recurren a Él día y noche. Este recurso a Dios día y noche es el que hacen los mártires que claman bajo el altar. Tenemos, pues, una serie de textos, tanto del A.T., como del N.T. que admiten el recurso a Dios con deseos de venganza e incluso de alegría, si Dios la ejecuta. Pero, entonces, se pregunta Agustín, ¿qué hacer con otra serie de textos que imponen lo contrario? Jesucristo imponía amar a los enemigos y hacer bien a los que nos odian (Mt 5,44). Pedro recordaba que no había que devolver mal por mal, ni maldición por maldición $(1 \mathrm{Pe} 3,9)$ y el mismo Pablo menciona que no hay que devolver a nadie mal por mal (Rom 12,17).

Es el momento de atar tantos cabos sueltos. Y lo hace razonando así: «Si no debe devolverse a nadie mal por mal, no sólo no debe devolverse un hecho malo por otro hecho malo; sino que tampoco un mal deseo por un hecho malo o por un mal deseo. Ahora bien, devuelve un mal deseo, quien, aunque él personalmente no se vengue, sin embargo, espera y desea que Dios castigue a su enemigo" ${ }^{44}$. Ahora bien, resulta que tanto el justo como el malvado desean que Dios se vengue de sus enemigos. Los textos citados donde aparecen justos deseando y alegrándose del castigo de los enemigos lo prueban. Luego habrá que hacer una distinción; y es ésta la que hace S. Agustín: «el justo desea que su enemigo sea más bien corregido que castigado; y cuando ve que es castigado por Dios, no se deleita en su pena, puesto que no le odia, sino en la justicia divina ya que ama a Dios» ${ }^{45}$.

Una vez llegados aquí, honestamente habría que preguntarle a S. Agustín para qué recurre al carácter profético de los Salmos. Este recurso se hacía para limpiar a los salmistas de todo deseo malo. Si ahora se admite que el justo desea e incluso se alegra al ver el castigo del justo, el recurso al carácter profético resulta inútil. Admite, pues, que en los Salmos hay deseos malos. Pero se cree obligado a hacer una precisión: «el justo si ve que es castigado el malo en este mundo, o se deleita por él si se corrige, o por otros a fin de que teman imi-

44. En. in Ps. 78,14: CC 39,1107.

45. Ib. 
tarle... Por tanto, por amor y no por malicia, es por lo que el justo se alegra cuando ve el castigo y lava sus manos, es decir, convierte más puras sus obras en la sangre, esto es, en el castigo del pecador (Sal 58,11)» ${ }^{46}$. Finalmente, después de insistir mucho en el tema termina con este principio. «Dondequiera que se lee en las escrituras que los justos odiaron a los hombres, se entiende, que odiaron sus vicios» ${ }^{47}$. Esta distinción puede estar bien, pero desde luego los Salmos no la hacen. Es el precio que hay que pagar por cristianizar los Salmos. Pero S. Agustín está dispuesto a pagarlo. Cuando comenta el Sal 101(100) no se le olvida aplicar el principio anteriormente citado. En el v. 3 lee: «facientes praevaricationem odio habui». Lo comenta de esta manera: «Odia a los prevaricadores, apártalos de ti... pero ten en cuenta que debes odiar a los prevaricadores, mas no a los hombres. Ved que el hombre prevaricador tiene dos nombres: el de hombre y el de prevaricador. Dios hizo al hombre; el hombre se hizo a sí mismo prevaricador. Ama en él lo que Dios hizo y destruye en él lo que él hizo" ${ }^{48}$.

Hemos visto anteriormente cómo interpreta el v. 11 del Sal 58(57): Laetabitur iustus cum viderit vindictam; manus suas lavabit in sanguine peccatoris». Cuando comenta el Salmo directamente, insiste en la misma interpretación, aunque con ligeras matizaciones. Hay, dice, un castigo futuro: el fuego del infierno; pero hay otro castigo oculto del que habla aquí el Salmo. El primer pecado es la soberbia, la última pena es el fuego eterno. Entre el primer pecado y la última pena se encuentran en medio pecados y penas. Ser adúltero, mendaz, avaro, defraudador, homicida son penas. A estas penas presentes y ocultas que padecen los malos es a las que refiere el Salmo en el versículo citado. «¿Qué significa, pues, lavará sus manos en la sangre del pecador? Que el justo, cuando ve el castigo del pecador, progresa y así la muerte de uno le sirve de vida a otro. Si, pues, corre espiritualmente la sangre de aquellos que interiormente mueren, tú viendo tal castigo, lava allí tus manos, vive más limpiamente en el futuro" ${ }^{49}$. La aplicación obtenida es fina, pero el Salmo ciertamente no hablaba de sangre espiritual.

\section{Salmos que niegan la existencia de la otra vida}

Esta idea aparece preferentemente en las lamentaciones, aunque también en las acciones de gracias. El fiel angustiado por la situación desgraciada en la que se halla, acude a Yahvé, para que intervenga en su favor. Entre los moti-

46. Ib. CC 39,1108 .

47. Ib.: «Et ubicumque in Scripturis sanctis leguntur in homines odia eorum odia fuisse vitiorum, quae ipse etiam unusquisque hominum oderit oportet in se si diligit se».

48. En. in Ps. 100,5: CC 39,1410.

49. En. in Ps. 57,21: CC 39,727-8. 

$\mathrm{Si}$, pues se entiende que en el infierno nadie confiesa a Dios, ¿cómo entonces explicar que el rico epulón en semejante situación confesara, o mejor, se viera obligado a confesar la justicia de Dios al ver a Lázaro feliz? Soluciona la dificultad diciendo que por muerte debe entenderse el pecado, que se comete despreciando la ley divina. Como el pecado es el aguijón de la muerte, puede perfectamente llamarse muerte al pecado. Entendida la muerte como sinónima de pecado, nadie efectivamente se acuerda de Dios, pues pecado es despreciar su ley y sus mandatos ${ }^{52}$.

Si hasta ahora la traducción no le ayudaba mucho para percibir la no creencia en la otra vida, no sucede lo mismo en el Sal 88(87). Este Salmo es la más tenebrosa de todas las lamentaciones del Salterio. Es la oración de un hombre al borde de la muerte, angustiado ante la visión del horrible Seol, del terrible silencio donde Dios no actúa. S. Agustín, como toda la tradicción cristiana, lo aplica a Cristo en su Pasión; lo que ciertamente es un atrevimiento, porque no hay salmo con menos esperanza en el más allá que éste. Refiriéndose al v. 5: «factus sum sicut homo sine adiutorio, inter mortuos liber; sicut vulnerati dormientes in sepulcris, quorum non est memor adhuc», razona así: Jesucristo de quien habla el Salmo fue tenido como hombre sin apoyo, como los heridos que duermen en el sepulcro, de quienes no te acuerdas aún. Nota Agustín cómo se afirma la diferencia entre Jesús y los demás muertos. Los que le mataron le creyeron semejante a los demás muertos, quienes todavía no han resucitado. Pero Jesús, en cambio, resucitó. La siguiente frase le causa mayor dificultad: «et ipsi expulsi sunt de manu tua». En el contexto del Salmo, evidentemente se refiere a los muertos; todos ellos según la concepción del A.T., están excluidos y separados de la mano de Dios. Pero esta idea para S. Agustín es inaceptable. Según él, los arrancados de la mano de Dios no son los muertos, sino los vivos, que hicieron que Jesús se pareciera a un muerto. Fueron privados de la ayuda de Dios quienes estimaron a Cristo sin apoyo. Añade expresamente que esta interpretación le parece mejor que referir la expresión a los muertos actualmente, pues éstos no han sido todos arrancados de la mano de Dios; entre ellos, en efecto, hay algunos que son justos, de quien todavía Dios no se ha acordado, haciéndoles resucitar, sin embargo sus almas están en las manos de Dios ${ }^{53}$. Más adelante y en el mismo Salmo encuentra el v. 11: «Por ventura harás milagros en provecho de los muertos». Agustín no puede

52. En. in Ps. 6,6-7: CC 38,30-31.

53. En. in Ps. 87,5: CC 39,1211: «Melius enim sic intellegendum existimo, quam ut id quod dictum est: Et ipsi expulsi sunt de manu tua ad illos referatur dormientes in sepulcro, quorum non meminit adhuc, cum sint in eis iusti, quorum licet non meminerit adhuc ut resurgant; de his tamen dictum est: Iustorum animae in manu Dei sunt, hoc est, habitant in adiutorio Altissimi... Sed illi expulsi sunt de manu Dei, qui Dominum Christum de manu eius expulsum esse crediderunt, quia eum inter iniquos deputatum occidere potuerunt». 
entender a los muertos físicamente, porque a éstos los resucitó (Mt 27,52). Luego debe entenderse de los hombres que de tal modo están muertos en el corazón, que no les movieron a la fe los grandes milagros de Jesucristo ${ }^{54}$. Esta espiritualización de los términos del Salmo la emplea al comentar el v. 13: «¿Por ventura se conocerán en las tinieblas tus maravillas y tu justicia en la tierra del olvido?». Las tinieblas, según él, indican a los infieles y la tierra del olvido es el hombre que olvida a Dios ${ }^{55}$. En definitiva aquí se valió de la espiritualización de los términos para salir airoso de la empresa. Tinieblas, muerte, sepulcro, tierra del olvido, etc., no son más que diversos términos para referirse al pecador, en cuyo estado evidentemente no se pueden percibir las maravillas de Dios.

Este somero sondeo es suficiente para observar cómo S. Agustín sale airoso de las dificultades que una cristianización de los Salmos siempre presenta. El recurso a la espiritualización de los Salmos, a alegorías caprichosas, a interpretaciones alambicadas es absolutamente imprescindible si se quiere leer los Salmos cristianamente. Sólo a este precio, un precio ciertamente caro, es posible salvar las dificultades.

Debe notarse que la alegoría es siempre una recreación del Salmo, es hacer un Salmo nuevo, que muy poco tiene que ver con el Salmo de la Escritura. Por eso extraña que se pueda afirmar que si uno tuviera que contentarse con solo dos comentarios a los Salmos escogería el de S. Agustín y el de Delitzsch. Que el comentario de S. Agustín «haga penetrar como ninguno en el sentido de los Salmos» ${ }^{56}$ es evidentemente una exageración. Más bien es cierto todo lo contrario: para la exégesis la autoridad patrística es de escasa importancia, especialmente en lo que se refiere al A.T. ${ }^{57}$.

\section{Mielgo \\ Estudio Teologico Agustiniano \\ Valladolid}

54. En. in Ps. 87,10: CC 39,1215: «Significat ergo isto verbo quod ait: Numquid mortuis facies mirabilia, homines corde ita mortuos ut eos ad vitam fidei tanta Christi mirabilia non moverent».

55. En. in Ps. 87,12: CC 39,1217: «Infideles enim significantur nomine tenebrarum... sic et terra oblita: homo est qui oblitus est Deum».

56. L. Alonso-Schoekel, Treinta Salmos: Poesía y Oración. Madrid 1981, 453-4.

57. R.E. Brown,-J.A. Fitzmyer,-R.E. MurPhy, Comentario bíblico «San Jerónimo». Madrid 1971, vol. V, 319. 